\title{
A RENDA DA TERRA E OS NOVOS PADRÕES DE OCUPAÇÃO URBANA EM ALFENAS-MG
}

\author{
Evânio dos Santos Branquinho
}

RESUMO: Este trabalho tem como objetivo principal analisar a intensa expansão urbana verificada em Alfenas-MG nas duas últimas décadas e as formas de ocupação resultantes. O grande número de empreendimentos imobiliários tanto populares quanto de alto padrão indica a expansão extensiva da mancha urbana, onde se constatam processos de especulação imobiliária e novas formas de segregação socioespacial. A lógica e a exploração da renda da terra urbana, associadas à financeirização, são fatores importantes de direcionamento do crescimento urbano. Nesse sentido, pode-se afirmar que se a cidade cresce "desordenada" pela ação ineficaz do poder público, esta acaba sendo "ordenada" pela aç̃̃es e interesses dos empreendedores imobiliários. No âmbito epistemológico, procura-se verificar os limites da teoria da renda da terra formulada em Marx em relação à dinâmica do mercado imobiliário atual. Portanto, torna-se importante caracterizar a dinâmica desses agentes produtores do espaço urbano e as contradições entre o valor de uso e o valor de troca da terra urbana, e as particularidades que esse processo assume na cidade de Alfenas-MG, considerando como uma cidade de porte médio, tanto em termos morfológicos quanto funcionais.

PALAVRAS-CHAVE: Expansão urbana; especulação imobiliária; renda da terra; segregação socioespacial.

\section{LAND RENT AND NEW URBAN OCCUPATION PATTERNS IN ALFENAS-MG}

ABSTRACT: This work has as main objective to analyze the intense urban expansion verified in Alfenas-MG in the last two decades and the resulting forms of occupation. The large number of both popular and high standard real estate projects indicates the extensive expansion of the urban area, where real state speculation processes and new forms of socio-spatial segregation take place. The logic and exploitation of urban land rent, associated with financialisation, are important factors in direction urban growth. In this way, it can be said that if the city grows "disordered" by the ineffective action of public authorities, it ends up being "ordered" by the actions and interests of real state entrepreneurs. In the epistemological scope, it seeks to verify the limits of the theory of land rent formulated in Marx in relation to the dynamics of the current real estate market. Therefore, it is important to characterize the dynamics of these agents that produce urban

\footnotetext{
${ }^{1}$ Doutor em Geografia e docente do Programa de Pós-Graduação em Geografia da Universidade Federal de Alfenas - MG. E-mail: evanio.branquinho@unifal-mg.edu.br
} 
space and the contradictions between the use value and the exchange value of urban land, and the particularities that this process assumes in the city of Alfenas-MG, considering it as a city medium-sized, both in morphological and functional aspects.

KEYWORDS: Urban expansion; real estate speculation; land rent; socio-spatial segregation.

\section{RENTA DE LA TIERRA Y NUEVOS PATRONES DE OCUPACIÓN URBANA EN ALFENAS-MG}

RESUMEN: Este trabajo tiene como principal objetivo analizar la intensa expansión urbana verificada en Alfenas-MG en las últimas dos décadas y las formas de ocupación resultantes. La gran cantidad de proyectos inmobiliarios, tanto populares como de alto nivel, indica la gran expansión de la expansión urbana, donde se producen procesos de especulación inmobiliaria y nuevas formas de segregación socioespacial. La lógica y la explotación de la renta del suelo urbano, asociada a la financiarización, son factores importantes para impulsar el crecimiento urbano. En este sentido, se puede decir que si la ciudad se convierte "desordenada" por la acción ineficaz de los poderes públicos, termina siendo "ordenada" por las acciones e intereses de los emprendedores inmobiliarios. En el ámbito epistemológico, busca verificar los límites de la teoría de la renta de la tierra formulada en Marx en relación con la dinámica del mercado inmobiliario actual. Por tanto, es importante caracterizar la dinámica de estos agentes que producen el espacio urbano y las contradicciones entre el valor de uso y el valor de cambio del suelo urbano, y las particularidades que este proceso asume en la ciudad de Alfenas-MG, considerándolo como un ciudad de tamaño medio, tanto en términos morfológicos como funcionales.

PALABRAS CLAVE: Expansión urbana; especulación inmobiliaria; renta de la tierra; segregación socioespacial.

\section{INTRODUÇÃO}

O município de Alfenas, localizado na mesoregião Sul/Sudoeste de Minas Gerais, com uma popuação estimada para 2021 em 80.973 habitantes (IBGE, 2021), nesses últimos anos, vem passando por uma nova escala de produção de seu espaço urbano e, portanto, de reprodução das relações sociais, especialmente, nas formas de consumo do espaço.

Chama a atenção a grande quantidade de novos empreendimentos em 
relação ao porte da cidade, em mais de uma dezena nesses últimos anos, revelando novas formas de exploração da renda do solo e de especulação imobiliária.

A explosão de novos loteamentos no entorno do Campus II da Unifal, a partir de sua implantação no bairro Santa Clara, é marcante; assim como a instalação de condomínios fechados de alto padrão na região do bairro Aeroporto, revelam as intensas desigualdades na reprodução desse espaço urbano, e manifestam novas formas de segregação e de autossegregação (BRANQUINHO, 2021).

Novos agentes produtores do espaço se sobressaem, como as incorporadoras, com sofisticadas estratégias de reprodução de capitais ligadas ao setor imobiliário acentuam modos exclusivos de consumo do espaço, como no caso dos condomínios fechados, por outro lado, a inércia geográfica de formas de reprodução do espaço permanecem, como a segregação da região dos bairros Primavera e Vista Grande.

Evidencia-se ainda a formação de uma periferia mais complexa, como no caso da região do Pinheirinho, onde novos usos do solo e classes sociais convivem próximas, mas apartadas, em função das elevadas disparidades socioeconômicas.

O objetivo principal deste trabalho é analisar a reestruturação do espaço urbano de Alfenas a partir dessas novas formas de ocupação como os condomínios fechados e demais empreendimentos, as estratégias de valorização, especulação, a ação do poder público, e seus impactos no espaço urbano, como a segregação. Desvendar essa nova fase de expansão urbana que ocorre de forma fragmentada e dispersa, considerando o porte médio da cidade em sua funcionalidade, tanto quantitativa como qualitativa.

\section{MATERIAIS E MÉTODOS}

Este trabalho apoia-se no método materialismo histórico e dialético e as 
formas em que este assume uma dimensão espacial, por meio, mas não só, da teoria da renda do solo. A partir desse delineamento, a cidade compõe um todo articulado e hierarquizado, a qual requer uma análise particularizada e abrangente, simultaneamente. A cidade como totalidade, onde intervenções em um ponto ou uma parte da cidade têm repercussões em outros locais da mesma. Considera-se também nessa escala intraurbana, em suas particularidades, centroperiferia, zonas de transição, formação de novas centralidades, infraestrutura e equipamentos urbanos. Em ambas as escalas, micro e macro urbanas, um processo de diferenciação espacial que se revela como crescimento desigual.

Visando às interações dialéticas entre padrões espaciais e processos sociais, para além da morfologia urbana, a dinâmica e a distribuição das classes e segmentos sociais, em suas práticas espaciais. Identificar os sujeitos, atores sociais e suas práticas, como agentes produtores do espaço, uma luta desigual pelos recursos, em que o espaço torna-se estratégico, superando assim um formalismo.

A regressão histórica ocorre à cidade capitalista da Revolução Industrial no final do século XIX, com base nas categorias da renda da terra e da propriedade privada do solo, fundamentais à consolidação da formação socioespacial capitalista, em sua trindade terra - trabalho - capital.

Em relação aos procedimentos metodológicos constam: levantamento bibliográfico, referente principalmente à discussão teórica sobre a renda da terra e sua espacialização; sobre a evolução urbana de Alfenas, assim como legislações municipais a respeito do ordenamento do solo urbano, jornais dos períodos de valorização imobiliária, entrevistas semi-estruturadas direcionadas aos agentes produtores do espaço (imobiliárias e empreendedor imobiliário); e registro fotográfico como instantâneos dessa reprodução.

\section{RESULTADOS E DISCUSSÕES}




\section{A LÓGICA DA RENDA DO SOLO URBANO E A ORDEM DA PROPRIEDADE PRIVADA}

No contexto da formação socioespacial capitalista, inicialmente, é importante considerar a cidade como o local de produção de um excedente social, de uma mais-valia geral, em função de suas economias de aglomeração, e sua apropriação que se dá de forma privada. Esta é a lógica da concentração dos fatores produtivos na cidade e sua funcionalidade do ponto de vista econômico, (vide o valor-localização e aglomeração), onde há uma complexa divisão social e territorial do trabalho. Portanto, essa riqueza produzida socialmente, é alvo de disputas por sua apropriação, pelas diferentes classes sociais, grupos e indivíduos.

Se a cidade e sua organização, do ponto de vista econômico, é uma grande concentração de meios de produção e de força de trabalho com a vistas a gerar maior eficiência produtiva por meio de economias de aglomeração, que permitem uma aceleração do tempo, a fim de produzir uma maior mais-valia coletiva, além do lucro e dos juros, parte desta é apropriada pela renda do solo urbano. O solo torna-se uma mercadoria especial, pois suas formas e estratégias de valorização são diferentes de outras mercadorias que têm a mobilidade como vantagem.

A terra urbana em si mesma pode não possuir nenhum valor no sentido de não conter nenhum trabalho acumulado nela, como no caso de um terreno vazio, mas tem um preço. Então como se constitui o seu preço, e mesmo um valor? Seu valor se constitui pelo trabalho incorporado nela como construções (capital fixo, bens de consumo), infraestruturas e serviços urbanos, que adicionam valor de uso àquele espaço (diferença entre terra e terra urbanizada) em termos de uma melhor localização, o que repercute em seu valor de troca, o qual se articula às leis da oferta e procura, mas também do monopólio.

De acordo com Singer (1983), sobre a atribuição dos preços da terra urbana diferentemente das outras mercadorias: 
Ao contrário do mercado dos produtos do trabalho humano, em que os preços giram ao redor de uma média constituída pela soma dos custos de produção e pela margem de lucro capaz de proporcionar a taxa de lucro média sobre o capital investido, os preços no mercado imobiliário tendem a ser determinados pelo que a demanda estiver disposta a pagar (SINGER,1982, p. 23).

É importante ressaltar que ao desenvolver a teoria da renda da terra, associada à teoria do valor, Marx ([1867] 2017) também expõe algumas indicações do significado de espaço geográfico, embora não o desenvolve no sentido da formulação de uma teoria e, mais especificamente, acerca do urbano. Como na passagem a seguir sobre a expansão das cidades, a especulação imobiliária e a distribuição das classes sociais no espaço urbano:

Qualquer observador imparcial pode perceber que, quanto mais massiva a concentração dos meios de produção, tanto maior é a consequente aglomeração de trabalhadores no mesmo espaço; que, portanto, quanto mais rápida a acumulação capitalista, tanto mais miseráveis são para os trabalhadores as condições habitacionais. É evidente que as "melhorias" (improvements) das cidades, que acompanham o progresso da riqueza e são realizadas mediante a demolição de bairros mal construídos, a construção de palácios para bancos, grandes casas comerciais etc., a ampliação de avenidas para o tráfego comercial e carruagens de luxo, a introdução de linhas de bondes urbanos etc., expulsam os pobres para refúgios cada vez piores e mais superlotados. Por outro lado, qualquer um sabe que o alto preço das moradias está na razão inversa de sua qualidade e que as minas da miséria são exploradas por especuladores imobiliários com lucros maiores e custos menores do que jamais o foram as de Potosi (MARX, 2013, p. 891, 892).

A exploração da renda do solo é a principal lógica/ordem subjacente à produção do espaço, de apropriação dos espaços urbanos e por ser uma mercadoria (de grande valor) tem implicações diretas na distribuição das classes sociais no espaço e portanto na segregação socioespacial.

A discussão sobre a renda do solo já estava presente nos economistas 
clássicos como Adam Smith e David Ricardo, mas é com Marx que ela avança como uma teoria crítica, fazendo parte de uma totalidade (a reprodução social) que compõe a mais-valia geral formada pelo capital-lucro, trabalho-salário, terrarenda fundiária (fórmula trinitária). Embora tenha ficado inacabada e mais voltada à renda do solo agrícola, no contexto da Inglaterra e de um capitalismo concorrencial do século XIX. Sua racionalidade é expandida ao solo urbano, onde adquire particularidades, conforme discutiremos adiante.

A renda fundiária pode ser definida como a parte da mais-valia captada pelo proprietário fundiário sob a forma de aluguel ou compra de uma parcela de terra, rural ou urbana.

Esse capitalista-arrendatário paga ao proprietário fundiário, ao proprietário da terra por ele explorada, em prazos determinados, digamos anualmente, uma soma em dinheiro fixada por contrato (exatamente do mesmo modo que o mutuário de capital monetário paga por ele juros determinados) em troca da permissão de aplicar seu capital nesse campo particular da produção. Essa soma de dinheiro se chama renda fundiária, não importando se é paga por terra cultivável, terreno para construções, minas, pesqueiros, bosques etc. (MARX, 2017, p. 824).

Marx distingue dois tipos renda da terra na economia capitalista em situações normais: a renda diferencial e a renda absoluta, e em situações especiais, a "renda de monopólio". Em essência, a renda diferencial que é a renda auferida pelo proprietário da terra em função das diferenças de fertilidade natural do solo, localização e produtividade artificial (insumos, máquinas etc.). Neste caso, o custo de produção de algum produto ligado ao solo é inferior ao preço médio de mercado. Em consequência, parte deste sobrelucro é captado pelo proprietário da terra sob a forma de renda.

A renda absoluta decorre da existência do monopólio da propriedade fundiária privada, mesmo a pior terra pode ser alocada ou comprada e gerar uma 
renda mínima. A instituição da propriedade privada da terra se coloca como uma barreira que o capital tem que pagar, seja na forma de aluguel ou em sua compra: "A propriedade fundiária só atua de maneira absoluta, como barreira, na medida em que condiciona o acesso ao solo em geral, enquanto campo de investimento de capital, ao pagamento de um tributo ao proprietário fundiário." (MARX, 2017, p. 993).

A renda de monopólio é o preço extra que os consumidores estão dispostos a pagar em função de uma qualidade excepcional de um produto, e não decorre dos fatores da concorrência ou da condição absoluta da propriedade privada da terra, ou seja da captação de uma renda além da diferencial e da absoluta, Marx dá o exemplo de vinhedos de excepcional qualidade.

Esse lucro extra, que aqui emana de um preço monopólico, transforma -se em renda e, desse modo, cai em poder do proprietário fundiário, devido a seu título sobre essa parcela do globo terrestre dotada de atributos especiais. Aqui, portanto, o preço monopólico cria a renda. (MARX, 2017, p. 1007).

Na transposição da renda do solo agrícola para a renda do solo urbano, embora a fertilidade não seja considerada, outros os atributos físicos do solo importam à ocupação, tais como a inclinação do terreno, a drenagem, as condições de erosão etc., Acrescenta-se valor ao solo, trabalho social acumulado, por meio de infraestrutura e equipamentos urbanos que incrementa a acessibilidade, e constitui um maior valor de uso, portanto, um maior valor de troca. A localização torna-se o fator mais importante:

Por fim, é claro que o progresso da produção social em geral tem, por um lado, efeito nivelador sobre a localização como causa da renda diferencial, porquanto gera mercados locais e, mediante o estabelecimento dos meios de comunicação e de transporte, cria espaço; além disso, ele aumenta as diferenças entre as localizações (MARX, 2017, p. 866, grifo nosso). 
Marx afirma que onde quer que exista a renda, a renda diferencial se coloca além das terras agrícolas. O avanço da produção capitalista aumenta a demanda por terras, como no espaço urbano, onde o aluguel de imóveis, corresponde a juros e amortização do capital investido no imóvel, com a mera renda sobre o solo:

Aqui, dois elementos entram em consideração: por um lado, a exploração da terra para fins de reprodução ou extração; por outro, o espaço requerido como elemento de toda produção e de toda ação humana. Em ambos os sentidos, a propriedade da terra exige seu tributo. A demanda de terrenos para construção eleva o valor do solo como espaço e fundamento, [...] (MARX, 2017, p. 1005, grifos nossos).

A citação anterior é essencial, uma vez que já se coloca a cidade como espaço da reprodução social, e a renda da terra é o fundamento da racionalidade dessa expansão. A figura do especulador já aparece separada do proprietário fundiário, e a especulação é o elemento chave, como no exemplo de Londres ao final do século XIX: “Nas cidades em crescimento rápido, particularmente onde a construção se realiza em escala industrial, como em Londres, o objeto principal da especulação não é o imóvel, mas a renda fundiária, [...]" (MARX, 2017, p. 1005).

A renda absoluta torna-se mais evidente na cidade, pois o monopólio da propriedade privada obriga os trabalhadores a alugar ou comprar uma habitação para ocupar o espaço urbano. E a renda de monopólio também está mais presente, como no caso de lojas localizadas em rodoviárias, shoppings, ou pontos exclusivos em função de paisagem, status, etc.

Marx apontava esse processo em Londres na segunda metade do século XIX:

Atualmente, nenhum empresário pode progredir sem construir com fins especulativos e em grande escala. O lucro obtido com a construção propriamente dita é extremamente pequeno; seu ganho principal consiste na alta da renda fundiária, na escolha e 
aproveitamento corretos do terreno para a construção (MARX, 2014, p. 360).

Evidentemente esse processo se transformou bastante desde o final do século XIX até o período atual, embora os fundamentos lógicos de exploração da renda da terra já estivessem colocados numa cidade industrial, não constituía uma fase de um capitalismo monopolista, financeiro e globalizado. A divisão do trabalho avançou em todos as áreas e, no setor imobiliário não foi diferente, novos agentes e segmentos se interpuseram visando captar parcela da mais-valia ligada à renda da terra, incorporadores, financiadores, construtores, corretores, seguradoras e a própria ação do poder público de diversas formas que assegura essa reprodução indica a complexidade que constitui atualmente o mercado imobiliário.

Já na articulação com outros setores, a interposição desses novos segmentos, a terra urbana e sua propriedade possibilitam não só uma renda mas um lucro, por meio do capital fixo e de juros ao capital financeiro. É nesse sentido que Harvey (2013) formula o conceito de "ambiente construído", intentando compreender as estratégias de reprodução dos capitais no meio urbano além da lógica da renda da terra.

Isso nos conduz à concepção de um ambiente construído que funciona como um sistema de recurso vasto, humanamente criado, compreendendo valores de uso incorporados na paisagem física, que pode ser utilizado para a produção, a troca e o consumo (HARVEY, 2013, p. 317).

Em decorrência das especificidades da circulação dos diferentes capitais no ambiente construído, os papeis dos agentes econômicos são reformulados, especialmente no atual estágio de um capitalismo monopolista e financeiro: 
Os proprietários de terra recebem renda, os empresários recebem aumentos na renda baseados nas melhorias, os construtores ganham o lucro do empreendimento, os financistas proporcionam capital monetário em troca dos juros, ao mesmo tempo que podem capitalizar qualquer forma de receita acumulada pelo uso do ambiente construído em um capital fictício (preço da propriedade) e o Estado pode usar os impostos (atuais ou antecipados) como suporte para investimentos que o capital não pode ou não vai realizar, mas que não obstante expande a base para a circulação local do capital (HARVEY, 2013, p. 503).

Portanto, cabe destacar a atuação do mercado imobiliário no processo de expansão urbana na atualidade e as particularidades que se verificam em Alfenas e suas especificidades de cidade média, portanto de influência regional, que passa a atrair mais investimentos de capitais imobiliários externos que atuam em escala ampliada e oferecem desde habitações populares produzidas em massa, com subsídios estatais, há novas formas de consumo do espaço, como os condomínios residenciais fechados de alto padrão.

\section{O MERCADO IMOBILIÁRIO E A EXPANSÃO URBANA EM ALFENAS}

Um período chave da estruturação urbana recente de Alfenas é a década de 1960, pois é nesse período que a industrialização do país avança, assim como as mudanças no campo, implicam diretamente na urbanização e, dessa forma, a necessidade de incremento da infraestrutura. Um caso representativo dentro desse quadro foi a construção da represa de Furnas para atender ao aumento da demanda energética, que teve como consequências a inundação de áreas, contribuindo para o aumento do êxodo rural, assim como para a desativação da malha ferroviária e a mudança para o modal rodoviário na região do Sul de Minas Gerais. Todos esses processos implicam em Alfenas, a superação da população rural pela urbana e de uma maior centralidade na rede urbana, passando a polarizar um conjunto de pequenas cidades em sua microrregião. O aumento de sua influência regional é o fator principal da transição de sua condição de cidade 
pequena para a de um centro intermediário.

A década de 1980 também é determinante, em função da reestruturação produtiva e da rede urbana brasileira, no contexto da mundialização financeira e de revolução técno-científica, há uma redefinição da divisão territorial do trabalho, com muitas cidades se especializando, dentro de uma rede mais articulada e competitiva (CORRÊA, 2006). Alfenas se consolida especialmente pela atratividade de oferta de serviços de ensino de nível superior e médico hospitalares; além de manter a captação de parte da renda gerada no campo.

A parir desse período de mudanças estruturais, podemos destacar algumas fases de sua urbanização, a partir das quais a produção do espaço se acelera e assume uma maior escala no âmbito intra-urbano, modificações em bairros e regiões da cidade, mas que têm implicações na cidade como um todo.

Ao final da década de 1950, pode-se destacar o loteamento do Jardim São Carlos e na década de 1960, o Conjunto Habitacional Vista Grande, contribuíram para definir a zona norte da cidade como uma região de moradia popular. Na década de 1970, os loteamentos Aeroporto, à leste, e Jardim da Colina, à oeste, vão definir as áereas de ocupaçõa da classe média-alta na cidade, embora o ritmo de ocupação nesse período fosse lento (PREFEITURA MUNICIPAL DE ALFENAS, 2006).

Na fotografia da Figura 1, a avenida Governador Valadares em 1969, sem pavimentação e sem iluminação pública, obtida no Jardim São Carlos com vistas ao centro da cidade, nota-se o grande vazio urbano criado entre estes.

Em 1988, a transformação da Fundação de Ensino e Tecnologia de Alfenas (FETA) em Universidade José do Rosário Vellano (Unifenas) aumentou o fluxo de estudantes, inflacionando o valor dos imóveis na zona sul da cidade, o que acabou expulsando moradores para as zonas oeste e norte. Também nesse período é construído o conjunto habitacional Francelino Pereira, pela Cohab, que configurou o bairro do Pinheirinho, na zona oeste. O residencial foi construído fora do 
perímetro urbano, ficando um "vazio" que foi sendo valorizado à medida que a infraestrutura era instalada, fomentando a especulação imobiliária. Ou seja, incorporou-se trabalho social à terra, transformando-a em terra urbanizada.

Figura 1 - Vista da avenida Governador Valadares em 1969

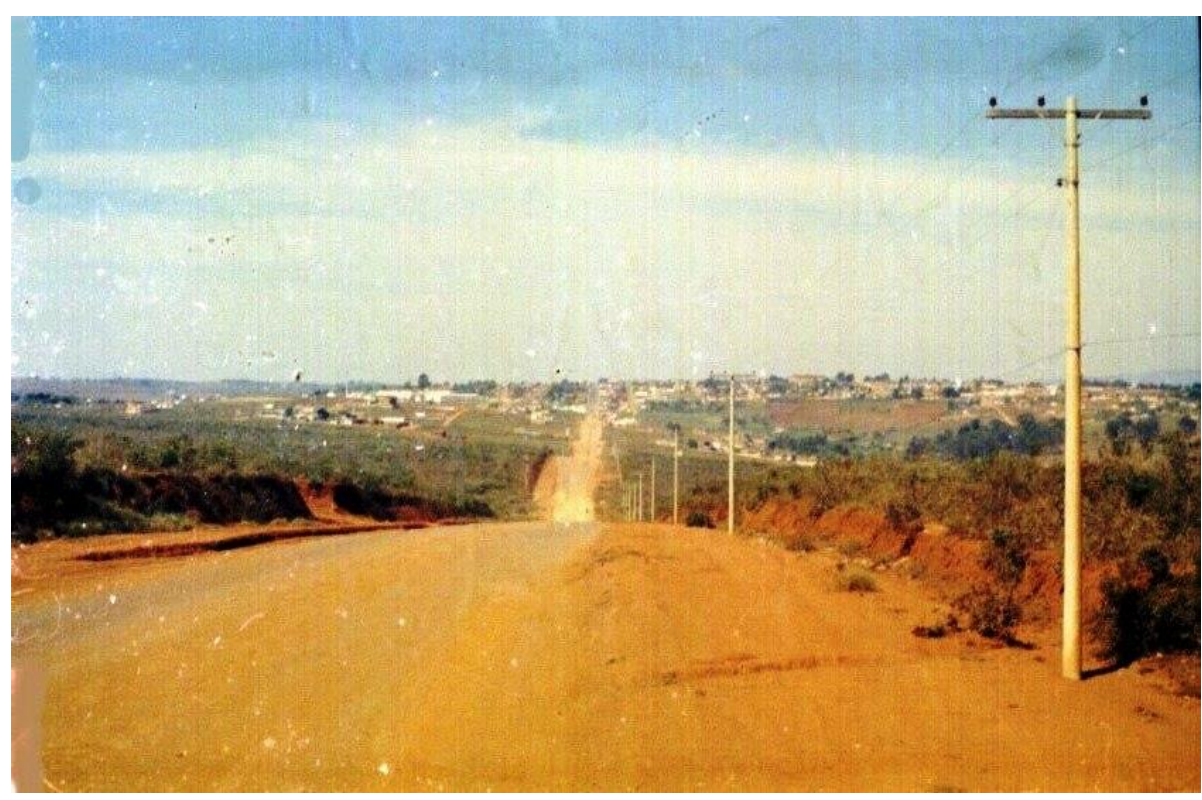

Fonte: João Bosco Oliveira Azevedo, 2017.

Na década de 2010, a instalação do campus II da Unifal no Santa Clara desencadeia uma expressiva valorização e especulação da região, com novos loteamentos voltados mais para classes médias, tendem a transformar o perfil da região, e expulsar a população de menor poder aquisitivo. Repetindo o processo de especulação imobiliária que ocorreu com a instalação da Unifenas.

Em 2012, o corretor da Imobiliária Castro, Ederson Landre de Castro, responsável pelas vendas dos lotes no Residencial Vale Verde, indicava a expressiva valorização dos terrenos: "O campus da Unifal influenciou muito o comércio imobiliário. Os primeiros lotes foram vendidos a $\mathrm{R} \$ 8 \mathrm{mil}$, mas agora as últimas unidades estão sendo vendidas a $\mathrm{R} \$ 33$ mil. As pessoas estão vendo o progresso nos bairros adjacentes" (ALFENAS HOJE, 2012).

Neste ano, o aposentado Jorge Mendes da Silva, de 76 anos, e sua esposa 
Sebastiana Teodoro de Souza, 73 anos, abriram uma lanchonete no bairro Santa Clara, segundo ele:

A Universidade vai trazer muitas coisas boas para nossa comunidade. Nós ficávamos meio esquecidos aqui, mas agora o prefeito Luizinho está fazendo bonito: casas novas no bairro, creche, faculdade. Temos até uma rádio aqui para escutar uma moda (de viola)" (ALFENAS HOJE, 2012).

O empresário José Lúcio de Souza, proprietário do Supermercado Pinheiros, afirmou que a instalação de conjuntos habitacionais e do novo campus da Unifal foram os principais motivos para ampliar o seu negócio. 0 Supermercado teve sua área ampliada de $550 \mathrm{~m}^{2}$ para 2 mil m², além de contratar mais funcionários, de 50 para 80. “Quando vi que esse lado da cidade estava se desenvolvendo bastante com a construção de conjuntos habitacionais, novos loteamentos e a Unifal instalando um novo campus, resolvi investir" (ALFENAS HOJE, 2012).

Em relação ao ensino superior, Alfenas é oitava cidade do país em fluxo de estudantes, de origem de outros municípios (IBGE, 2020), o que contribui para o aumento da demanda por moradias, elevando seus preços, principalmente de locação, o que contribui para o aumento da demanda por moradias, elevando seus preços, principalmente de locação.

Entre os anos de 2010 e 2016, houve um total de 16 loteamentos na cidade, sendo seis condomínios residenciais fechados. Antes desse período a cidade tinha apenas um condomínio fechado. Entre as estratégias de produção desses espaços está a prefeitura que incentiva esse tipo de empreendimento como uma forma de diminuir os custos de manutenção da infraestrutura e serviços públicos, pois nessas áreas a responsabilidade é do próprio condomínio, implicando assim na privatização do espaço público (AZEVEDO, 2016).

Mudança dos agentes produtores do espaço: agora empreendedores 
imobiliários, ligados â financeirização, e externos à cidade, a uma articulação mais complexa da rede urbana. Junção de proprietários fundiários tradicionais e empreendedores não locais que veem a possibilidade de elevados ganhos, como no exemplo do Grupo Sequóia, empreendedor dos condomínios fechados Floresta e Cidade Jardim. Na Figura 2 a seguir, o Condomínio Residencial Floresta loclaizado em frente ao bairro popular Santos Reis, é bastante evidente as diferenças de densidade de ocupação, ordenamento e os padrões das residências.

A condominização, refletindo em diversos serviços voltados a esse setor e valorização de espaços que tendem a expulsar atividades e população de menor poder aquisitivo para áreas mais distantes do centro, definindo setores espaciais na mancha urbana mais evidentes em termos da distribuição das classes sociais, embora esse processo em Alfenas, apesar de ser segregada ainda é incipiente e comparativamente a cidades maiores.

Figura 2 - Vista do Condomínio Residencial Floresta

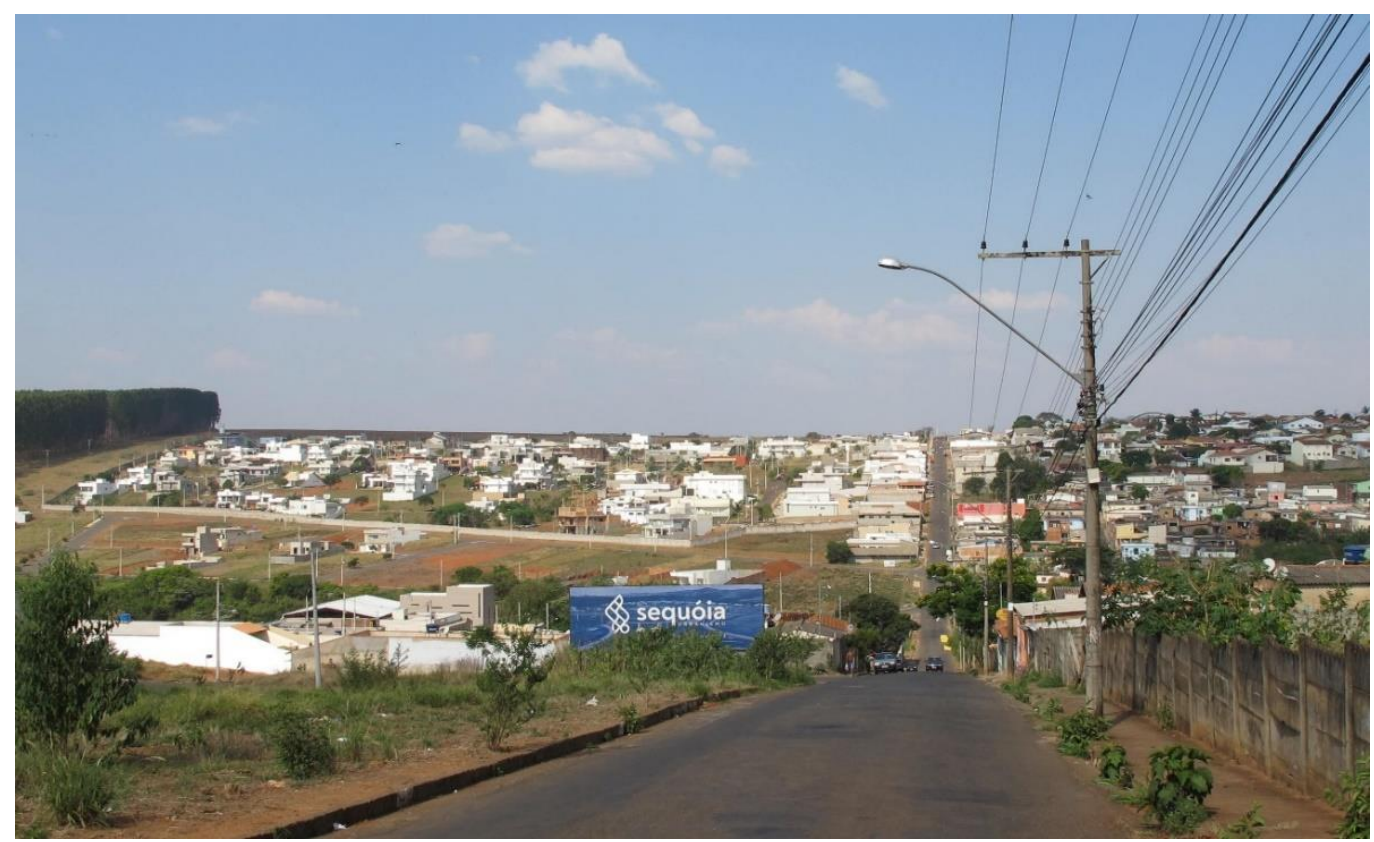

Fonte: Evânio S. Branquinho, outubro de 2020. 
Atualmente, a construção da avenida Perimetral Oeste, concluindo o anel viário em torno da cidade, é um momento importante de intensificação da produção do espaço urbano, com o espaço sendo vendido no "atacado", por meio de grandes parcelamentos e novos loteamentos. Como indicou Villaça (2007), a acessibilidade é um dos principais fatores de valorização do espaço. A mobilização da propriedade, com a transformação da terra rural em urbana, conforme exposto na Figura 3 a seguir.

Se a urbanização está ligada à contínua divisão técnica do trabalho e à diferenciação de classes e estratos sociais, quais os contornos esta assume no atual momento de avanços técnicos de reestruturação capitalista, portanto, nas relações de produção e consumo, inclusive de espaço?

O que justifica essa grande quantidade de empreendimentos? Em períodos de crise e de juros baixos, a extração da renda por meio da propriedade imobiliária é uma das alternativas de ganhos, os imóveis tornam-se investimentos e não propriamente o seu uso como moradia, o mais importante é o seu valor de troca, o rendimento que ele pode gerar através do aluguel ou de sua venda posterior, sua valorização (especulação), isso aponta também para uma financeirização do solo urbano.

Figura 3 - Trecho da implantação da avenida Perimetral Oeste na área rural de Alfenas 


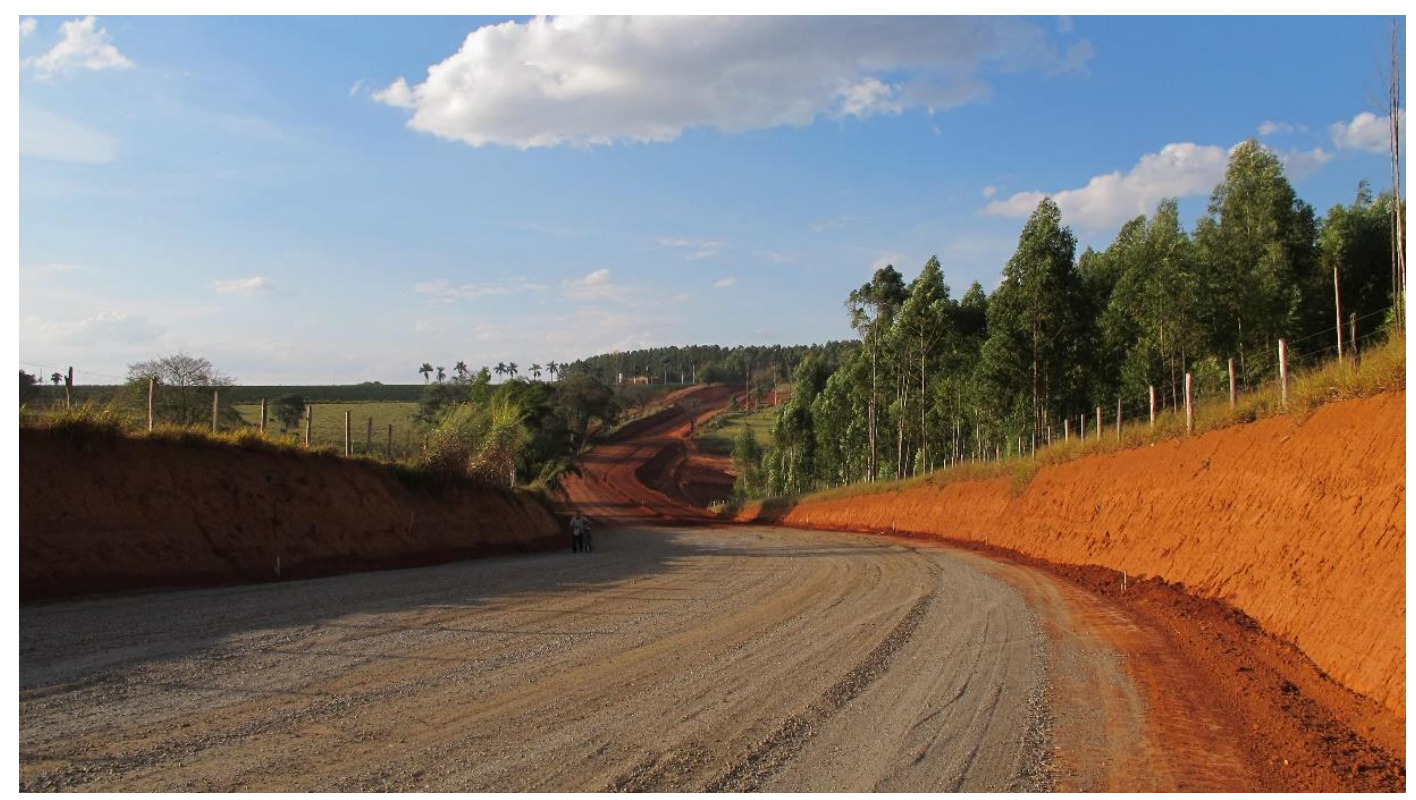

Fonte: Evânio S. Branquinho, junho de 2021.

Na Figura 4 a seguir, o recém loteamento Júlio Alves, o terceiro, próximo à avenida Perimentral Oeste e ao Residencial Oliveira, onde as imobiliárias indicaram um dos maiores índices de valorização.

Figura 4 - Novo loteamento Júlio Alves próximo ao Residencial Oliveira

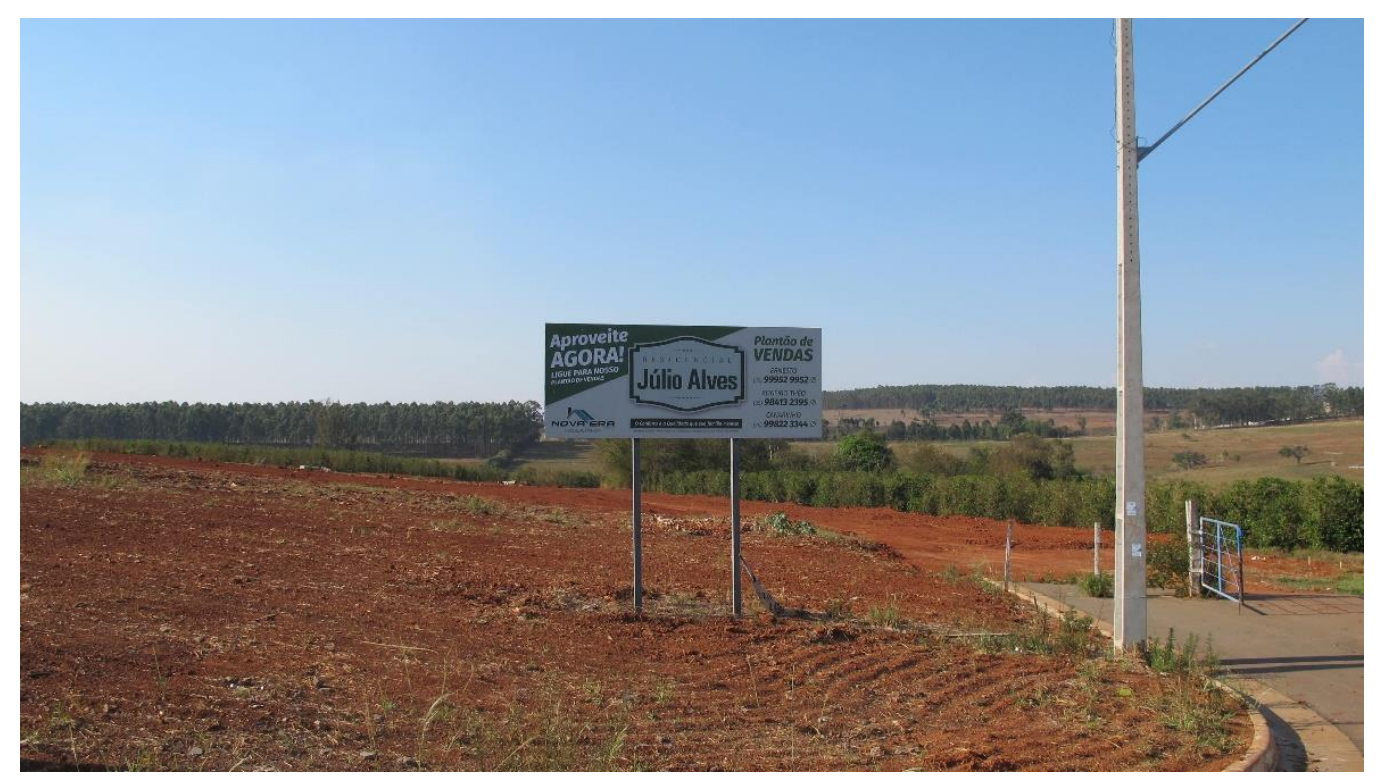

Fonte: Evânio S. Branquinho, setembro de 2021.

É o que afirma o corretor de imóveis José Batista Marques, Zerley Imóveis, 
sobre a aquisição da casa própria, em que dá o exemplo do residencial Dona Anita, com 140 lotes, vendidos em apenas dois dias. A aquisição dos lotes se dá de forma parcelada, a maioria dos lotes adquiridos foram financiados, com parcelas em média de quinhentos reais mensais (O ALFENENSE, 2021).

A ação do poder público continua sendo um dos principais agentes dessa expansão atual, dos conjuntos habitacionais aos condomínios fechados, promovendo nas três esferas do poder (municipal, estadual e federal) o "ajuste espacial", atuando contra a queda tendencial das taxas de lucro, conforme destaca Harvey (2013).

Em momentos de crise, principalmente, o poder público faz grandes investimentos em obras de infraestrutura, em intervenções que os capitais privados não têm capacidade de investir, em função do longo tempo de circulação, de retorno do investimento e, portanto, mais vulnerável a crises e depreciações, o autor denomina esse momento de "inércia geográfica". O Estado intervém para alavancar a reprodução de capitais privados, seja através de subsídios, financiamentos ou na construção (HARVEY, 2013).

O setor da consrução civil é tido como menos vulnerável às crises por contar com poíticas governamentais de recuperação econômica, ações anticí́clicas. Nesse sentido, torna-se um setor estratégico das políticas habitacionais, com o financiamento deste setor em função de sua capacidade de gerar empregos, e movimentar a economia através da cadeia de outros setores que a ele se articula (materiais de construção, movéis, eletrodométicos).

Em decorrência, também ocorre uma valorização diferenciada dos espaços pelas intervenções do poder público, através das melhorias na infraestrutura e nos serviços públicos. Ao decidir a localização dessas intervenções que se traduzem em melhorias e valorização do espaço, gera rendas diferenciais.

Opoder público também age por meio da aprovação de leis, como a de regularização fundiária, que intenciona inserir a população mais carente na 
cidade, superando a barreira da renda absoluta; assim como na circulação econômica. Antecedendo esta ação, pode ocorrer a doação de lotes pela prefeitura (ou concessão de uso). Do ponto de vista político, essa ação, na maioria das vezes, clientelista, disseminada no país, rende votos.

Nesse quadro, também pode se estabelecer um mercado imobiliário paralelo, quando os moradores realocam apartamentos de programas habitacionais, subdividem e revendem lotes, pois não estão livres da valorização imobiliária e oportunidades de auferir uma renda, especialmente, em períodos de dificuldades financeiras.

De acordo com Bolaffi (1982, p. 42), a habitação vira um "falso problema", pois não há o interesse em resolvê-lo de fato, mas de explorar essa situação, como a ideologia da casa própria. Cai na esfera do político, numa estratégia de poder, para manter a riqueza concentrada, a propriedade de um lado e a expropriação de outro (relações de propriedade), na reprodução das desigualdades, em que a ideologia da casa própria torna-se central.

Sobre a lei de regularização fundiária no município de Alfenas, aprovada em 2018, traz em seu artigo primeiro:

$\S 1^{\circ}$ Para os efeitos desta Lei, considera-se Regularização Fundiária o conjunto de medidas jurídicas, técnicas, urbanísticas, ambientais e sociais, que visam à regularização de núcleos urbanos informais, trazendo-os para a formalidade, com o fito de garantir o direito à moradia e a qualidade de vida da população (PREFEITURA MUNICIPAL DE ALFENAS, 2018).

O poder público municipal aprovou o Plano Diretor em 2006, todavia nunca regulamentou os zoneamentos de uso, ocupação e parcelamento do solo, o que ordenaria, se aplicado efetivamente, a ocupação do espaço urbano. Sem essa regulamentação, o capital imobiliário tem "terra livre" para atuar e a cidade acaba sendo "ordenada" pelos interesses privados dos empreendedores imobiliários, 
nos quais a exploração da renda da terra é o objetivo principal.

A Lei No 3941 de 12 de dezembro de 2006, que instituiu o Plano Diretor Participativo do Município de Alfenas, traz em seu artigo 21:

Serão passíveis de edificação compulsória os vazios urbanos com área superior a $5.000 \mathrm{~m}^{2}$ (cinco mil metros quadrados), lotes vagos com área superior a $500 \mathrm{~m}^{2}$ (quinhentos metros quadrados) ou com o CA inferior a $10 \%$ (dez por cento), daquele permitido para a referida macrozona (PREFEITURA MUNICIPAL DE ALFENAS, 2006).

A lei, fundamentada no Estatuto da Cidade de 2001, estabelece os instrumentos para combater os vazios urbanos, ou a retenção especulativa de terras, como no caso do IPTU progressivo no tempo, contudo sem regulamentação, fica sem aplicação. Em geral, as prefeituras não aplicaram este instrumento, pois contraria diretamente os interesses dos setores e capitais imobiliários.

Nem o Plano Diretor foi atualizado, passados 16 anos de sua aprovação. Como afirma Rolnik (2012), sobre um descolamento entre a legislação dos planos diretores e a ação do poder público, no caso da habitação:

Sob o mesmo contexto econômico político a política habitacional atual é concebida e praticada como elemento de dinamização econômica para enfrentar uma possível crise e gerar empregos, colocando-se de forma desarticulada com uma política de ordenamento territorial e fundiária destinada a disponibilizar terra para moradia popular. O resultado é um extraordinário aumento no preço de terras e imóveis (ROLNIK, 2012, p. 100).

O papel do Estado na reprodução das relações sociais de produção, em que sua relação com o espaço, revela sua natureza contraditória, a intervenção deste, como no caso dos vazios urbanos, tanto pode liberar a terra para um uso social que atenda mais ao interesse público, no exemplo das Habitações de Interesse Social, como pode liberar a terra para usos mais lucrativos ao capital imobiliário. 
Como síntese desses processos, com base nas pesquisas de campo realizadas, a atrbuição do valor do solo urbano em Alfenas, a partir da ação dos agentes imobiliários na conversão desses valores em preços são considerados principalmente a área do terreno e/ou da área construída, a topografia, a infraestrutura e a localização. Esta útima, em termos de proximidade do centro, de serviços coletivos e equipamentos públicos, mas também, citado por todos os entrevistados ${ }^{2}$, a proximidade de conjuntos habitacionais e áreas onde os índices de criminalidade, como o tráfico de drogas, são elevados, o ritmo de ocupação acaba sendo mais lento.

Percebe-se também na determinação dos preços aspectos intangíveis e subjetivos, derivando para a especulação, pois estão longe dos custos de produção, e até mesmo de forma comparativa com outros imóveis semelhantes. Foram relatados diversos exemplos, especialmente de imóveis de alto padrão, em que os promotores imobiliários lançavam um preço bastante elevado e esperavam/especulavam se o "mercado" absorveria aqueles preços. Em caso negativo, os preços foram reajustados para baixo; no caso das vendas se realizarem, acabou sendo um parâmetro para o reajuste de outros imóveis/empreendimentos, inflacionando o mercado.

Os valores de localização, que tem um peso significativo na atribuição dos preços do solo urbano, são na prática intangíveis, o que abre uma grande oportunidade para a especulação, ou seja, quando os preços se descolam dos valores. Corrobora com o que Singer (1982) afirmou sobre o uso do solo urbano ser regulado pelo mecanismo do mercado e seu preço ocorrer por aquilo que a população pode pagar, e não exatamente pelos custos de produção.

Sobre a questão da grande quantidade de novos loteamentos e se existe uma demanda efetiva, os corretores afirmaram que sim, os quais cerca de $30 \%$

\footnotetext{
${ }^{2}$ Realizadas em novembro de 2021, em duas imobiliárias e uma loteadora e imobiliária.
} 
desses imóveis ou terrenos são adquiridos para fins de valorização/especulação. Eles ressaltaram que havia uma demanda reprimida, pois até 2008 , a prefeitura não autorizava muitos loteamentos e, a partir desse período, houve maior liberalização desses empreendimentos. Portanto, a ação do poder municipal como regulador importante dessa expansão urbana. Um outro fator essencial destacado, sobretudo em relação aos empreendimentos populares, são as linhas de crédito oferecidas, quando da existência destas, as vendas e a ocupação são aceleradas.

\section{CONSIDERAÇÕES FINAIS}

A polarização regional que Alfenas exerce na condição de cidade média, a atratividade da rede de serviços, com um alcance espacial maior do ensino superior, contribui para o aumento da demanda por moradias, elevando seus preços, principalmente de locação.

A partir da desconcentração industrial e populacional das áreas metropolitanas, as cidades médias tornam-se atrativas para fluxos de investimentos e estratos sociais, a exemplo da expansão de empreendimentos imobiliários, como os condomínios fechados, que atraem um público voltado ao consumo desses espaços privados, acentuando a segregação urbana.

$\mathrm{Na}$ esfera da produção do espaço, verifica-se uma mudança dos agentes produtores do solo urbano, em que a aristocracia fundiária articula-se aos empreendedores imobiliários externos, o primeiro, disponibilizando a terra, o segundo, o capital, as técnicas construtivas e o financiamento.

Enquanto na esfera do consumo do espaço, o crescimento do número de loteamentos, mesmo na crise, ou por isso mesmo, a lógica da renda do solo como captação de parte da mais-valia urbana, atua diretamente na orientação do crescimento urbano e na distribuição das classes sociais no espaço urbano, leiase segregação socioespacial. 
Atualmente há grande oferta de lotes na cidade, por outro lado, há uma demanda não solvável por moradia, pois estes lotes não estão disponibilizados para resolver o problema da moradia em Alfenas, mas para a venda a quem pode pagar e para captar a renda da terra.

A retenção especulativa da terra contribui para a maior expansão horizontal da cidade, em que os vazios urbanos, em áreas com infraestrutura e serviços coletivos, têm como consequências a elevação do valor da terra, dos imóveis, das infraestruturas e dos transportes.

Essa forma de ocupação das áreas urbanas, majoritária nas cidades brasileiras, conduz à necessidade de rediscutir a função social da propriedade urbana, pois há uma distância expressiva entre o que a legislação e os planos preveem e a realidade, ou seja, as contradições entre o concebido e o vivido. A ideologia da casa própria torna-se uma estratégia de política habitacional, que não tem por finalidade resolver essa demanda, mas explorar relações clientelistas entre o poder público e a população desassistida.

Não desvinculada de coalizões com os interesses privados, a ação do poder público na produção do espaço é marcada por contradições, a qual mesmo em intervenções de melhorias de infraestruturas e equipamentos urbanos em locais mais precários, no longo prazo, ocasionam a valorização imobiliária e a expulsão dos moradores de menores rendimentos, reproduzindo segregações e, mais recentemente, uma padrão disperso da mancha urbana.

\section{REFERÊNCIAS BIBLIOGRÁFICAS}

ALFENAS HOJE. Novo campus da Unifal eleva preços imobiliários na região do Pinheirinho. 17.03.2012. Disponível em: https://alfenashoje.com.br/noticia.asp?id_noticia=4978. Acesso em: 24.08.2021. AZEVEDO, João Bosco Oliveira. Memórias de Alfenas, 2017. Disponível em: 
https://www.facebook.com/groups/1155401031254752/search/?q=avenida\%20g overnador\%20valadares. Acesso em: 23.11.2021.

AZEVEDO, Lilian Mara de Castro. Alterações socioespaciais decorrentes do processo de condominização residencial na cidade de Alfenas/MG. Trabalho de Conclusão de Curso em Geografia, Universidade Federal de Alfenas-MG, 2016.

BOLAFFI, G. Habitação e urbanismo: o problema e o falso problema. In: MARICATO, Ermínia (Org.). A produção capitalista da casa (e da cidade) no Brasil industrial. 2 ed. São Paulo: Alfa-omega,1982.

BRANQUINHO, Evânio dos Santos (org.). A produção do espaço segregado em Alfenas-MG. Alfenas-MG: Editora Universidade Federal de Alfenas, 2021.

CORRÊA, Roberto L. Estudos sobre a rede urbana. Rio de Janeiro: Bertrand Brasil, 2006.

HARVEY, David. Os limites do capital. São Paulo: Boitempo, 2013.

INSTITUTO BRASILEIRO DE GEOGRAFIA E ESTATÍSTICA (IBGE). IBGE Cidades@. Disponível em: https://cidades.ibge.gov.br/brasil/mg/alfenas/panorama. Acesso em: 23.11.2021.

INSTITUTO BRASILEIRO DE GEOGRAFIA E ESTATÍSTICA (IBGE). Regiões de Influência de Cidades de 2018 (REGIC). Rio de Janeiro: IBGE, 2020.

MARX, Karl. O capital: crítica da economia política. Trad. Rubens Enderle. São Paulo: Boitempo, livros 1, 2 e 3, 2013, 2014, 2017.

PREFEITURA MUNICIPAL DE ALFENAS. Lei $n^{\circ} 4792$ dispõe sobre a regularização fundiária no município de Alfenas, 10 de maio de 2018.

PREFEITURA MUNICIPAL DE ALFENAS. Lei n 3941 de 12 de dezembro de 006, institui o novo Plano Diretor Participativo do Município de Alfenas.

O ALFENENSE. Crise não afeta setor imobiliário e de construção civil em 
Alfenas.18.08.2020.

Disponível

em:

https://www.oalfenense.com.br/noticia/155/crise-nao-afeta-setor-imobiliario-ede-construcao-civil-em-alfenas. Acesso em: 24.08.2021.

ROLNIK, Raquel. 10 Anos do Estatuto da Cidade: Das Lutas pela Reforma Urbana às Cidades da Copa do Mundo. In: RIBEIRO, Ana Clara Torres et al. (org.). Leituras da cidade. Rio de Janeiro: Letra Capital: ANPUR, 2012, p. 87-104.

SINGER, Paul. O uso do solo urbano na economia capitalista. In: MARICATO, Ermínia (org). A produção capitalista da casa (e da cidade) no Brasil industrial. São Paulo: Alfa-Omega, 1982

VILLAÇA, Flávio. Espaço intra-urbano no Brasil. São Paulo: Studio Nobel, 2007. 